\title{
BLOGGING: AGENCY, MINDSET AND LITERACY
}

\author{
Vera Lucia Menezes de Oliveira e Paiva \\ Universidade Federal de Minas Gerais
}

Junia de Carvalho Fidelis Braga Universidade Federal de Minas Gerais

\begin{abstract}
In this article, we discuss the concepts of agency, mindset and literacy in order to investigate, in the light of complexity theory, three groups of teachers and their blogging practices. Our aim was to check if formal teaching of digital technologies has 'disturbed' the traditional literacy behavior of our participants and changed their mindsets. We visited their blogs to check if they went on blogging after the end of the course and emailed them a questionnaire to learn about their experiences with this new literacy and to collect their opinions about blogging. We realized that just a few blogs were relatively active and that the majority of the teachers had not incorporated this new literacy into their teaching practices. Nevertheless, the results do not allow us to state that those teachers have not changed their mindsets because they might have migrated to other digital contexts.
\end{abstract}

Keywords: Blog, literacy, agency, complexity, mindset.

\begin{tabular}{|l|l|l|l|l|}
\hline Ilha do Desterro & Florianópolis & n 66 & p. 075- 100 & jan/jun 2014 \\
\hline
\end{tabular}




\section{Introduction: Literacy, mindset and the Internet}

Freire repeatedly emphasized that "literacy cannot be viewed as simply the development of skills aimed at acquiring the dominant standard language" and that for "the notion of literacy to become meaningful it has to be situated within a theory of cultural production and viewed as an integral part of the way in which people produce, transform, and reproduce meaning" (Freire, 1987, p. 98). The same is said by Lankshear and Knobel (2006, p. 64) when they define literacies as "socially recognized way of generating, communicating and negotiating meaningful content through the medium of encoded texts within contexts of participation in Discourses (or, as members of Discourses)".

With the emergence of the Internet and the birth of different communication tools and new genres (e.g. webpages, chat, twits, etc), the concept of "new literacies" comes into play. Lankshear and Knobel $(2006,2007)$ understand that new literacies involve new "technical stuff" and new "ethos stuff". As examples of "technical stuff" we have the digital technology with which to write and read, but, in our opinion, it is the "ethos stuff" that makes all the difference.

When we say that new literacies involve different "ethos" stuff" from that which is typically associated with conventional literacies we mean that new literacies are more "participatory", "collaborative," and "distributed" in nature than conventional literacies. That is, they are "less expert-dominated" than conventional literacies. The rules and norms that govern them are more fluid and less abiding than those we typically associate with established literacies. (Lankshear \& Knobel, 2007, p. 9) 
Lankshear and Knobel (2006, p. 29) also argue that "'new' literacies are related to an emerging and evolving mindset" which they define as "a general way to think about the world". According to them,

The idea of mindset usually refers to a point of view, perspective, or frame of reference through which individuals or groups of people experience the world, interpret or make sense of what they encounter, and respond to what they experience. Mindsets can be thought of as sets of assumptions, beliefs, values, and ways of doing things that orient us toward what we experience and incline us to understand and respond in some ways more than others. (2006, p. 31)

They add that "the concept of mindset is useful for thinking about literacy education specifically, and learning more generally, under current historical conditions" (p. 31).

The world has changed with the advent of the Internet. Technology affords new ways of being and doing things, as discussed by Lankshear and Knobel (2007). Printed material in the classroom has been complemented by hypermodal texts and teachers are expected to act beyond the classroom. Each day a different tool is created for communication and collaboration.

According to Rheingold (2012, p. 4), there are "five literacies that are in the process of changing our world: attention, participation, collaboration, the critical consumption of information $\left(\mathrm{aka}^{1}\right.$ "crapdetection"), and network smarts". Network smarts can be understood as the power of creating networks and getting things done in one's network. It is our contention that teachers are supposed to occupy a central position in their networks to connect students and other school members. 
Blogging is a good example of a digital tool and new literacy practices emerge as a consequence. But before talking about blogs, we need to discuss agency in the light of complexity theory.

\section{Agency and complexity}

Language is essentially a means of agency. We use language to act on our environment and change it. On the other hand, we are also influenced by the environment and undergo a series of changes, one of which is our communicative behavior. We share the assumption, proposed by Paiva (2011, p. 74), that language is a "dynamic non-linear adaptive system made up of a connection of bio-cognitive-social-historical-cultural-political elements that allow us to think and act within society". This definition leads us to the concept of agency.

Ahearn (2001, p. 112) offers a provisional definition for agency: "Agency refers to the socioculturally mediated capacity to act", but she concludes that this definition "leaves a great deal unspecified. For example, where is agency located? Must agency be human, individual, collective, intentional, or conscious?" (p. 130). For Picard (2010, p. 4), "agency is an immutable characteristic of individuals that allows humans to act and to speak". He adds that

Modern definitions of agency are unable to account for the radical interconnectivity that exists between humans, nonhumans and environments. In this sense, the recognition that humans participate in diverse relationships with nonhumans and environments leads to redefinitions of agency. Because Modern notions of agency are problematized by both Foucault's thought and complexity theory, I argue that new definitions will emerge. (Picard, 2010, p. 3) 
We will try to answer Ahearn's questions in the light of complexity systems. As Johnson (2007, p. 13) pointed out, a complex system "contains a collection of many interacting objects or 'agents'. In the case of markets, they are traders and investors. In the case of traffic, these are drivers". In the case of digital genres, we would say that the agents are writers, readers and also robots (such as the googlebot which finds new content on the web and adds it to the Google index). Therefore, we can now answer the first part of Ahearn's question and state that agents, and consequently agency, are not only human but also non-human and collective.

Johnson (2007, p.13) adds that "interactions between these agents may arise because the agents are physically close to each other, or because they are members of some sort of group, or because they share some common information".

As "the study of Complexity is synonymous with the study of agents and network together" (Johnson, 2007, p. 13), we consider that agency is a key concept when dealing with complex systems due to their inherent dynamism.

According to Menezes (2013, p.65), "an agent is one who acts and whose actions can be motivated or constrained by other elements in the system and by other systems." She adds that "agency changes the system, but we can never predict the impact of one's autonomous choices and actions."

Further evidence of agency in complexity is the fact that behaviors are affected by feedback. Jonhson (2007, p. 14) explains that by saying that "this means that something from the past affects something in the present, or that something going on at one location affects what is happening at another - in other words, a sort of knock-on effect". In the case of blogs, we may say that readers and comments added to the posts are essential feedback stimulating bloggers to go on feeding their blogs. 
Complex systems are also adaptive and that means that "an agent can adapt its behavior by itself, in the hope of improving performance". Blogs, for instance, may lure a greater number of readers, if they appear among the first choices offered by a search engine. Luring more readers will contribute to the emergence of more comments, that is, more energy to the system.

Complex systems are open and "can be influenced by the environment, just like a market can be influenced by outside news about the earnings of a particular company - or the traffic is affected by the closure of a particular road" Johnson (2007, p. 14). We can further state that blogs are highly affected by the environment. Their content can be linked to or reproduced by other blogs, which consequently increases the number of readers. The same can happen with the number of comments or the amount of feedback. If a blog remains ignored and if its owner does not post new content, it tends 'to die'. In other words, if agency from blog owners and readers/writers does not bring energy to blogs, they will not evolve and will not form a dynamic network that feeds information back into the system.

Another important point to be highlighted, as Picard (2010, p. 2) claims, is that "agency is generated within ecological limits and within the constraints imposed by power relations". We agree with Picard (2010, p. 7) that "because complexity theory recognizes that complex systems include humans, nonhumans and environments, it provides a theoretical legitimation for a radical relational agency". We also agree that "complexity theory makes it clear that human isolation from environments and from nonhumans is impossible; there are no purely social relations of power because complex systems are always both social and ecological" (Picard, 2010, p. 7).

Bearing this in mind, we analyzed blogs produced by teachers as literacy processes which evolve within social and ecological 
environments through dynamic and complex interactions among all the agents involved in blogging relational agency.

\section{Blogs and teaching practices}

At the turn of the century, teachers in language classrooms around the world were becoming acquainted with newly-arrived multimedia computers and broadband access to the Internet. Since the beginning of this century, with the success of blogs, teachers have felt compelled to change their mindsets and consequently the way they interact with their students and the way they deal with teaching and learning materials.

The word blog is a short form for weblog (web+log) and its origin dates back to the 1990s, according to the Oxford Dictionary ${ }^{2}$. Although blogs are a well-known digital genre, it is worth quoting the description found on Schmidt (2007, p. 1409). According to him,

Weblogs, or "blogs", are frequently updated websites where content (text, pictures, sound files, etc.) is posted on a regular basis and displayed in reverse chronological order. Readers often have the option to comment on any individual posting, which is identified by a unique URL. Through such comments and references to other online sources in the posting, as well as through links to favorite blogs in the sidebar (the "blogroll"), blogs form a clustered network of interconnected texts: the "blogsphere".

In addition to displaying multimodal content, blogs afford asynchronous interaction and stimulate communication and collaboration among the members of that social network. Their social nature and their interacting agents as well as their capacity 
to influence and be influenced by other systems and to give and receive feedback can be considered some of the hallmarks of complex systems.

Blogs afford and expand audience and give both teacher and students the opportunity to bring into their teaching and learning practices more opportunities for language use. Blogs have proved to be an efficient support for academic literacy practices (Gebhard, Shin, Seger, 2011). In addition, blogs also say something about their authors. As highlighted by Knobel and Lankshear (2007, p. 4), "when we look at somebody's weblog we might well find that much of the meaning to be made from the content has to do with who we think the blog writer is: what they are like, how they want to think of themselves, and how they want us to think of them".

Although blogging places literacy within the context of today's digital information landscape, Miller and Shepherd (2004), Miller (2012), and Warlick (2007) argue that publishing views and ideas to a given community or large audience dates back to a few centuries ago. Miller and Shepherd argue that although it is not possible to create a detailed "family tree of blogs", one can discern some major features: "marked reverse-chronological structure, the frequent updating, the combination of links and commentary, and simultaneous intrinsic and extrinsic purposes". According to Miller and Shepherd (2004), one of the main branches of the blog family tree sprouts from the use of blogs as filtering or directory services for the internet.

Miller and Shepherd (2004) also consider that genres related to collecting and organizing information can be thought of as part of the blog family tree. Another related branch of the family tree is occupied by genres of political journalism, such as the pamphlet, the editorial, and the opinion column. Such genres highlight commentary. In the seventeenth and eighteenth centuries, political 
opinion was often expressed through independent publications called pamphlets or broadsides, which became known as vehicles for political protest and propaganda.

Warlick (2007), relying on his skills as a history researcher and as a blogging educator, also found that the social nature and origin of the blog pointed to the eighteenth century. According to Warlick, at the time, "there were no computers, the Internet ran on horseback" and yet, something very similar to blogging was happening. A new class of literate citizens was rising in Europe and in the American colonies. Meanwhile, paper was becoming cheaper to produce and printing presses and print shops were appearing in larger towns, which enabled people to report their views to wide audiences in the form of pamphlets.

In line with Miller and Shepherd (2004), Warlick (2007) reminds us that towards the end of the twentieth century, a condition occurred similar to that which gave rise to pamphlets: when personal computers became linked to the World Wide Web, people were able to publish their ideas to a global audience through basic web navigation skills. This in essence paved the way for those who wanted to share views and ideas with their readers.

This bird's eye view of the concept of blog and its family tree is in tune with the idea that new literacy practices emerge from the evolution of systems, are driven, organized and reorganized by a process here understood as agency. As Larsen-Freeman and Cameron (2008, p. 190) argue, "when we use the genres in speaking or writing, we use the stabilized patterns but exploit the variability around them to create what is uniquely needed for that particular literacy or discourse event". Blogging seems like an ideal teaching aid because it can create a social network which enables both teacher and students to go beyond the classroom walls and interact in an open social 
system. Such a system can attract collaborators other than teachers and students, which can enrich knowledge and resource sharing, reflection, criticism, and promote enlightening discussions. Blogs are chosen because of their multimodal communicative possibilities in education context, user-friendliness and the interaction afforded between the blog owner and his audience, as readers can also contribute by posting content, making criticism or asking questions.

In this line, Miller and Shepherd (2009) add that the number of blogs has grown exponentially since the 90's and new blogging technologies have rapidly developed and adapted. But this growth is not simple or linear as blogs change, adapt and expand. No sooner had we grown accustomed to online diaries than $\mathrm{j}$ (ournalism)blogs, travel blogs, campaign blogs, etc. started popping up on the web. "With the rapidity equal to that of their initial adoption, blogs became not a single phenomenon but a multiplicity"(p. 263). The authors also state that due to the technological nature of the blog, a native to the web, it is inherently linked, public, malleable and volatile.

Drawing on the concept of affordance ${ }^{3}$ (Gibson, 1986), Miller and Shepherd (2009) defend that blogs provide interaction, connection, immediacy and instant access and, as such, they are not a genre in themselves but rather a "constellation of affordances". The authors emphasize that when blogging technology first became available through hosting sites, it fit a particular exigency arising in the 90's but with the evolution of technology and the engagement of multiple users, the cluster of affordances multiplied repeatedly and "the suite of affordances called blogging was discovered to fit other exigencies in different ways, so other types of blogs proliferated"(p. 281).

Other features of a blog include reverse chronology, links, comments, etc. These features can be considered established patterns. 
Inspired by Jamieson's Darwinian approach to genre, Miller and Shepherd (2009, p. 284) consider that the recurrence of these patterns may be understood as a "chromosomal imprint of ancestral genres" that resists change.The idea that people find different affordances in blogs to produce meaning in situated contexts is in tune with the idea of literacy in Freire (1987) and in Lankkerd and Knobel (2006). Personal blogs, travel blogs as well as educational blogs may afford new ways of being and doing. Moreover, blogs allow interconnectivity between humans, non-humans and the environment to take place while learning emerges in a participatory and distributed way.

As pointed out by Picard (2010:13),

Ecological relations and relations of power are not static. Such vast and interconnected relationships between humans, nonhumans and environments make up the complex socialecological systems in which we exist and, as a result of such complex interactions, unpredictability is characteristic of complex systems.

Researchers have been investigating several aspects of blogs in educational contexts. For instance, Godwin-Jones (2003) points out the role of blog for online collaboration for both language professionals and learners; Williams \& Jacobs (2004), and Hemi, Bayne \& Land. (2009) discuss the use of blogs in higher education; Kim (2008) presents his model for the use of blogs in educational contexts; and Dippold (2009) shows that blogs are valuable tools for peer feedback.

Silva (2013) analyzed 32 research reports from 2000 to 2012 whose common theme was the pedagogical use of blogs. These studies, selected from the research database available at Capes, the Brazilian Federal Agency for the Support and Evaluation of 
Graduate Education, reveal possibilities as well as limitations regarding the use of blogs in the educational context.Some of the recurrent patterns found in the research include collaborative learning, reflection on pedagogical practices, the development of reading skills in both Portuguese and English, contact with a variety of genres, the development of self-esteem promoted by the validation of student's different skills posted in educational blogs, and the use of blogs as a space for interaction between school management and the local community.

As for the limitations, Silva points out that teachers claim that the use of technology can be time consuming as it requires preparation and may result in an overload of work. In addition, teachers emphasize the need to develop technological competence and the lack of broadband Internet and good equipment. In her study, Silva (2013) also reveals that teachers tend to use a course design based merely on the transmission of information. Despite these limitations, several of these works presented an array of affordances of blogs and show that the successful use of blogs in the classroom will depend on several elements and how these agents interact in a given context.

All these studies confine themselves to the school environment, but our main concern is whether the teachers in our courses who use blogs in educational contexts will go on blogging beyond the classroom. Our main question is "has our continuing educational program promoted new literacies"?

It is our contention that the emergence of digital communication technologies has highlighted the importance of leading teachers to the realm of cultural productions and new ways of writing. 


\section{The research context}

With this in mind, our research group at Universidade Federal de Minas Gerais has been offering since 2009 a 360-hour graduate course on Language and Technology. We are aware that in-service teachers are increasingly required to be involved with new literacies. Hence the need to meet their demand for learning to deal with the digital world and to use new digital tools for teaching and learning. Our goal is to make our teacher-students use technologies to change their mindsets so that they can produce hypermodal texts and act beyond the classroom.

We contend that urging teachers to use digital technologies in their classrooms is a way to motivate them to exert agency and to go beyond the textbooks. As Picard (2010:31) reminds us "the exclusion of certain human beings from agency denies them the full participation within Modern social systems".

The syllabi for the in-service teacher education courses include support for the participants to create blogs and to use several digital tools-such as glogster, bookr, podcasting, puzzle makers-for content development. It is our expectation that blog owners will go on posting after their courses.

We have been asking ourselves whether our participants' mindset has really changed and whether their experiences in our courses have, in fact, affected their social practices.

\subsection{The research questions}

In this section, we will focus mainly on the participants' use of blogs in order to answer three questions. (1) Do teachers continue 
to post on their blogs after their course ends? If not, why? (2) How do these teachers react to the new digital affordances? (3) Does the formal teaching of digital technologies 'disturb' the traditional literacy behavior of our participants and change their mindsets?

\section{Participants and Method}

The 88 participants in our research are language teachers who have attended a two-year course on computer assisted language teaching which is part of a Certificate Program of the graduate course at a public university. One of the requirements of the course was to set up a blog. Most of the participants had never done it before.The first group created blogs in 2009, the second in 2010 and the third in 2011.

In order to answer our research questions, we analyzed data collected about blog building during our courses for in-service teachers since 2009. In 2013, we visited again all the 88 blogs created during three years to see if they were still active. As far as content is concerned, we focused mainly on the affordances they provide, as our intention was not to discuss the posts of the blogs. We also analyzed answers provided to a questionnaire (see appendix I) emailed to our former student teachers. Only $13(14,77 \%)$ teachers filled in the questionnaire. The data were analyzed in the light of complex/chaos theory.

\section{Data analysis}

During the three courses, 88 blogs were created: 22 in 2009, 31 in 2010 and 35 in 2011. Eightof these 88 blogs had updates up to 2012 ( 4 from the first group, 3 from thesecond, and 1 from the third) and 6 of these blogs are still active in 2013 (1 from the first group, 3 
from the second, and 1 from the third).But the updates in those blogs do not mean those teachers are really active bloggers. They do not post regularly and neither receive comments. Most of them exhibit only one or two messages in 2012 and 2013.

Among the 6, one was created before the course. Another thing worth mentioning is that the owner of one of the blogs chose to create a website but included in it features of a blog, such as comments and posts, list of members, latest activities, etc. This teacher is now giving online classes of English for Specific Purposes to students from different parts of the country and refers to the hundreds of followers of his site as a community.

The most frequent theme is language teaching and the updates carried out in all the blogs followed the original subject matter proposed. The choice of theme was motivated by the characteristics of the course and by the fact that the participants had been encouraged to post the educational activities designed during the course.

It is worth noting that course participants showed an interest in creating the blogs. The act of choosing a title for the blog as well as resources such as images, colors and videos reflect the involvement of the teachers in this process. Some of them detailed the objectives of their blogs, often accompanied by warm greetings to their readers.

The following excerpts from the forum of the course illustrate their involvement in using this media. In (1) Sarah ${ }^{4}$ indirectly announces the creation of her blog and demonstrates she still has some difficulties and a classmate immediately cheers her up in the sequence.

(1) Colleagues,

Today I created my blog which is only starting out and I still need to figure out how to post text, images and all the material that I want but don't know yet.

But the address is http://XXXX.blogspot.com/. 
I'll be waiting for your visit and collaborations.

Best, Sarah.

Sarah, you'll adapt soon enough! If you need some help, you can count on me.

Another kind of feedback can be found in excerpt 2. A course participant notices the potential of multimodal resources for the development of listening skills. It's also interesting to notice that for this participant, blog viewers, in this case students, should be invited to post comments for interaction to take place.

(2)Your blog is great! Here are some suggestions so that your blog can become a learning space in the Portuguese as additional language area (only suggestions, ok?): I suggest that your posts be accompanied by some proposal that helps the learning process. For example, you put a video about $\mathrm{BH}$ and my suggestion would be to put a short tagline: Watch a video about $\mathrm{BH}$. Which tourist attractions are mentioned in the video? Send comments on your experiences of the tourist spots shown in the video, etc. The student could watch for entertainment or use an input to develop the language. This could be a standard in your blog. For the church, you could put links about architecture: Read more about...to promote reading opportunities, etc.

Excerpt (2) also shows feedback from one participant. In both cases, peers create collaborative agency events in showing interest in their peers' work, offering assistance and instruction. Although we consider that comments added to the posts are essential for stimulating bloggers to go on feeding their blogs and crucial to bring 'energy' to the blogs, course participants did not feel encouraged to post feedback in their peers' blogs but rather chose to do so in TELEDUC, the virtual learning environment in which the course 
took place, either at the portfolio or forum of the course. Also, such affordance may have been disregarded due to the fact that creating a blog was part of the course tasks and at that point it was not used as a medium for communication.

Course participants seem to react differently to the use of digital affordances. Most of them (75 teachers) simply learned to use the tools planned in the courses, like blog, Voki, glogs and podcasts, and stopped blogging when the course was over. As only 12 teachers filled in the questionnaire, we do not know for sure the true reason for the discontinuity of their blogs. Either they realized that carrying on was no longer suitable or they had built their blogs only to attend the requirements of our course. Yet, the 13 teachers who managed to go beyond the classroom and integrate tools and elements in their blogs made possible the emergence of new affordances, promoting new opportunities for learning. Some of the affordances found include:

a. links to news websites so as promote reading opportunities and engage students' participation in different discourse communities;

b. links to websites related to teacher education, opening up opportunities to establish different kinds of interaction between teachers rather than only between teachers and students;

c. Links to social online dictionaries, tools such as Wordle, electronic translators, etc. These resources may promote further practice of lexical items.

d. Links to social networks and feeds have also been found and may be considered a strategy to maximize interaction with other 
92 Vera Lucia M. de O. e Paiva, Junia de C. Fidelis Braga, Blogging: ...

users and facilitate access to new posts and comments. In one of the blogs, although there are no comments, the blogger included a counter which shows that the blog is still active if we consider the number of viewers. In this case the large number of visitors might be explained by the use of feeds that let users know when there is something new in the blog.

e. Videos and images with rich input for language teaching and learning found in the blogs also play an important role in the process of language learning as they can be used to develop listening skills and experience multimodal communicative possibilities.

f. The affordances listed seem to promote different types of learning opportunities. Keeping educational blogs active can also be understood as the emergence of a new ethos and a way to create 'network smarts' considering that active blogs enable both the development of different learning communities and the culture of continuing education as bloggers have to search for new resources and be open to new ideas in order to update their blogs.

Although the blogs updated present several affordances, comments were rarely found. The lack of interaction with viewers might be one of the reasons for the presence of sparse posts.

The answers to the last question indicate that other dynamics observed allow us to identify that the 'systems go through perturbations' of different natures. The updated educational blogs, for example, provide evidence of the discussions promoted during the courses in presenting new educational proposals developed with tools utilized in the material creation courses. Other positive 
instances are reported in the following answers, including a teacher who was rehired after successfully using an educational blog in an elementary school:

(3) My project was related to the application of an English learning blog for the $5^{\text {th }}$ grade of Elementary School (2011). The results were so positive in my subject and others that I was rehired in the school on the condition of continuing the same work with the $5^{\text {th }}$ year students in 2012 .

(4) I use my blog as support in the classes where I use the computer room and I also post activities and tasks to be done at home. The blog is already known among the students as a space that contains important subject information and material. The school already refer students to the blog when they look for information on the school site about the subject I teach.

Other teacher reports demonstrate aspects that allow us to make the case for the relational character of agency under the terms of Picard (2010). The contextual perturbations and relations influenced the actions of course participants as in the case of the teacher who deactivated her blog due to a lack of readers in (5), a lack of time mentioned in (6) and the teacher who withdrew from the teaching activity in (7).

(5)After the course ended, I posted on the blog for a few months but seeing as there were no students and I don't work as a teacher anymore, I didn't have any reason to keep updating my blog.

(6)Actually, I didn't have time to continue managing my blog, but I plan on doing it when the course ends. Maybe I'll create a blog to interact with my students as well, to finish my project, 
since it is one of the tools that I would use, according to the preproject.

(7) Since I don't have any current activity linked to teaching, I wasn't motivated to keep up the blog I created for the specialization subject. The blog that I maintain with a friend is about other subjects.

Questionnaire data indicate that all the respondents considered blogging an easy task, but their answers also show that some contexts do not offer the energy necessary for the evolution of systems and, consequently, for the emergence of actions, organizations and reorganizations that promote new literacy practices. One teacher said she had not enough time to go on blogging and two claimed their schools did not value the use of blogs.

Apart from these perturbations, we could also cite the new media that are in competition with the blog, as is the case of the teacher who said she chose to deactivate her blog and migrate to a social network, as we can see in (8).

(8) My online literature blog is inactive, as I now use Facebook to support my High School classes. I think I get more visits and followers among the students, seeing as I've had a better response using this tool. For my Third Level groups I continue to use my blog or network as support for my classes.

We would stress that the blogs that were updated by the teachers show they are inserted in situated contexts and seem to feed and be fed by other systems. Moreover, the creation of blogs often fulfills specific objectives, whereby its creator may render it active or inactive depending on the context in which the blog is inserted. The following answer illustrates these issues: 
(9) I needed a specific reason for each blog I created. Both blogs that I had before the specialization course and the one I created on starting the course were set up with one purpose: post assignments for a certain course. The only difference between them was that in the former I was requesting assignments teacher - and in the latter I was required to do the assignments - student. When the course finished, the blog automatically stopped being updated, either by the teacher (in the former case), or by the students (in both cases). It is a natural process, since the learning processes in foreign language, undergraduate and specialization courses, to name just a few, take place over periods and it is not always the same teachers that continue certain tasks assigned by other teachers. I think that the continual updating/feeding of a blog would only be successful if it involved an educational project with all the teachers that give classes to a certain group. As such, in each stage, subject, or semester a teacher would update the blog with his/her respective activities.

This last comment reinforces the idea that agency is motivated or constrained by other elements in the system and that mindset is changed if the agent is well motivated by its context. Changing mindset is not a choice, but a way of thinking which is also constrained by situated experiences. One does not change the way one teaches simply because one has learned to use a digital tool. One must be "involved in an educational project" which requires a new mindset or a new literacy, a project that focuses on innovation, collective intelligence, interaction, collaboration and sharing.

\section{Conclusion}

The discussions presented are in alignment with the thinking of Larsen-Freeman and Cameron (2008: 73) who argue that "in a complex perspective, context and environment are inseparably 
connected in the system, not background against which the system operates. Systems may be coupled, with one acting as dynamic context for the other".

It is worth noting that, often, with the aim of interacting with other systems we come across other agents and/or systems that can change the course of our original actions and efforts and, as a result, our practices. The results of our investigation corroborate the findings of Paiva (2013) that the actions of an agent may be promoted or curbed by other elements in the system itself or other systems and that agency changes the system, but does not allow us to predict the impact of autonomous choices and actions.

We believe that there is a heightened, and possibly inappropriate, expectation that teachers should change their mindsets and produce blogs and other educational resources overnight, going from being a reproductive agent of knowledge to a productive one. Besides, we forget that they may also utilize material from other websites and even from blogger colleagues to integrate technology in the classroom.

Finally, we would like to go back to Freire's notion of literacy, especially when he views it as "an integral part of the way in which people produce, transform, and reproduce meaning"(p. 98). The fact of abandoning their blogs does not mean those teachers are not digitally literate. They might be producing, transforming, and reproducing meaning in other digital contexts and using different tools, as the one who is now using Facebook and the other who has created a homepage for his English course for pilots.

Our courses offered the teachers different tools for participation, collaboration and sharing, i.e, new literacies. They were challenged to change their points of view, by living different experiences in the digital learning environment. We hope that we have spread the seeds for a new ethos and consequently for new mindsets. 


\section{Notes}

1. Aka is an acronym for "also known as".

2. http://www.oxforddictionaries.com/definition/english/blog? $\mathrm{q}=\mathrm{blog}$

3. Gibson (1986) developed an interactionist view of perception and action based on information that is available in the environment. For Gibson "the affordances of the environment are what the environment offers the animal, what it provides or furnishes, either for good or ill”(p. 127)

4. The names of the teachers are pseudonyms.

\section{References}

Ahearn, L, M. (2001) Language and agency. Annual Review of Anthropology 30,109-37.

Dippold, D. (2009). Peer feedback through blogs: Student and teacher perceptions in an advanced German class, ReCALL. 21 (1), 18-36.

Freire, P.\& Macedo, D. (1987). Literacy: reading the word and the world. London: Routledge.

Gibson, J.J. (1986)The Ecological approach to visual perception. Hillsdale, New Jersey: Lawrence Erlbaum.

Gebhard, M., Shin, D.\&Seger, W, (2011) Blogging and emergent L2 literacy development in an urban elementary school: A functional perspective. CALICO Journal, 28(2):1-29.

Godwin-Jones, R. (2003). Emerging technologies: Blogs and wikis environments for online collaboration.Language, Learning \& Technology. 7 (2), 12-16.http://lt.msu.edu/vol7num2/emerging/default.html

Hemi, A; S. Bayne \& R. Land. (2009). The appropriation and repurposing of social technologies in higher education. Journal of Computer Assisted Learning 25, 19-30.

Johnson, N. (2007) Simply Complexity: a clear guide to complexity theory. Oxford: OneWorld.

Kim, H. N. (2008). The phenomenon of blogs and theoretical model of blog use in educational contexts. Computers \& Education 51, 1342-1352. 
Lankshear, C. \&Knobel, M. C. (2007) Sampling "the new" in new literacies. In: Knobel, M.; Lankshear. A new literacies sampler (Eds). New York: Peter Lang. p. 1-24.

Lankshear, C. \&Knobel, M. (2006). New Literacies: Everyday practices and classroom learning (second edition). Maidenhead and New York: Open University Press.

Larsen-Freeman, D. \& Cameron, L. (2008) Complex Systems and Applied Linguistics. Oxford: Oxford University Press.

Menezes, V. (2003) Chaos and the complexity of SLA. In: BENSON, Phil\& Cooker, Lucy (Eds.). The Applied Linguistics individual: sociocultural approaches to autonomy, agency and identity. (pp.59-74) Sheffield, UK; Bristol, USA: Equinox.

Miller, Carolyn R.\& Shepherd, Dawn. (2004) Blogging as social action: A genre analysis of the weblog. http://blog.lib.umn.edu/blogosphere/ blogging_as_social_action.html?referer=http\%3A\%2F\%2Fworks. bepress.com\%2Fdawn_shepherd\%2F2\%2F.

Miller, C. R.\& Shepherd, D. Question for genre in the blogosphere. (2009) In: Giltrow, J.\&Dieter S. (Eds.), Genres in the Internet: Issues in the Theory of Genre. 263-290.

Miller, C. R. (2012) Questões da blogosfera para a teoria de gênero. In: Dionisio, A. P. (Org.) \& HOFFNAGEL, J. C. (Org.). Gênero Textual, Agência e Tecnologia de Carolyn R. Miller. (pp. 87-112). Rio de Janeiro: Parábola.

Paiva, V.L.M.O. (2011) Linguagem e aquisição de segunda língua na perspectiva dos sistemas complexos. In: Burgo, V.H., Ferreira, E.F.\& Storto, L.J. Análise de textos falados e escritos: aplicando teorias. (pp. 7186). Curitiba: Editora CRV.

Picard, E. K. (2010) A radical relational agency: Foucault, complexity theory and environmental resistances. PhD thesis, University of Nottingham, UK. http://etheses.nottingham.ac.uk/1450/, Access Dec.4, 2013.

Rheingold, H. (2012) Net smart: how to thrive online. Cambridge, London, The MIT Press, 2012. Kindle Edition.

Schmidt, J. (2007) Blogging practices: An analytical framework. Journal of Computer-Mediated Communication (pp. 1409-142712). International 
Communication Association. http://onlinelibrary.wiley.com/doi/10.11 11/j.1083-6101.2007.00379.x/pdf

Silva, L. F. C.O (2013) Uso pedagógico do Blog: análise de pesquisas acadêmicas postadas no Banco de teses da CAPES. Dissertação. Belo Horizonte, Centro Federal de Educação Tecnológica.

Warlick, D. F. (2007) Classroom blogging: A teacher's guide to the blogosphere. (second edition). North Carolina: The Landmark Project.

Williams, J. B. \& Jacobs, J. (2004) Exploring the use of blogs as learning spaces in the higher education sector. Australasian Journal of Educational Technology, 20 (2), 232-247.

(Recebido em 03/01/14. Aceito em 01/04/14) 
100 Vera Lucia M. de O. e Paiva, Junia de C. Fidelis Braga, Blogging: ...

\section{Appendix I}

Name:

Do you have a blog? If so, what is the URL?

Tick the answers that apply:

( ) I use my blog to support my teaching activities.

( ) I prefer a personal blog to an educational one.

( ) I do not have a blog nor do I intend to have one.

( ) I used to have a blog, but gave up on it.

( ) I find it easy to set up and manage a blog.

( ) I find it difficult to build and manage a blog.

( ) I had a blog before this certificate course.

( ) I plan to use a blog for pedagogical purposes in the future.

( ) I do not have time to manage a blog.

( ) My school does not encourage me to use a blog.

( ) I do not use a blog because I do not get paid extra for this task.

( ) I would use a blog if my colleagues had one.

( ) I only set up a blog because the certificate course required students to do so.

( ) I did not continue to feed the blog after the certificate course. If you have ticked this item, please explain why you did not continue to feed your blog. 